\title{
Investigation of the Role of the Domain Linkers in Separate Site Catalysis by Clostridium symbiosum Pyruvate Phosphate Dikinase ${ }^{\dagger}$
}

\author{
Min Wei, Dongmei Ye, and Debra Dunaway-Mariano* \\ Department of Chemistry, University of New Mexico, Albuquerque, New Mexico 87131
}

Received June 21, 2001; Revised Manuscript Received August 9, 2001

\begin{abstract}
Pyruvate phosphate dikinase (PPDK) catalyzes the reversible reaction: ATP $+\mathrm{P}_{\mathrm{i}}+$ pyruvate $\leftrightarrow$ AMP $+\mathrm{PP}_{\mathrm{i}}+\mathrm{PEP}$ using $\mathrm{Mg}^{2+}$ and $\mathrm{NH}_{4}{ }^{+}$ions as cofactors. The reaction takes place in three steps, each mediated by a carrier histidine residue located on the surface of the central domain of this threedomain enzyme: (1) E-His + ATP $\leftrightarrow$ E-His-PP·AMP, (2) E-His-PP·AMP $+\mathrm{P}_{\mathrm{i}} \leftrightarrow$ E-His-P + AMP + $\mathrm{PP}_{\mathrm{i}},(3) \mathrm{E}-\mathrm{His}-\mathrm{P}+$ pyruvate $\leftrightarrow \mathrm{E}-\mathrm{His}+\mathrm{PEP}$. The first two partial reactions are catalyzed at an active site located on the N-terminal domain, and the third partial reaction is catalyzed at an active site located on the C-terminal domain. For catalytic turnover, the central domain travels from one terminal domain to the other. The goal of this work is to determine whether the two connecting linkers direct the movement of the central domain between active sites during catalytic turnover. The X-ray crystal structure of the enzyme suggests interaction between the two linkers that may result in their coordinated movement. Mutations were made at the linkers for the purpose of disrupting the linker-linker interaction and, hence, synchronized linker movement. Five linker mutants were analyzed. Two of these contain 4-Ala insertions within the solvated region of the linker, and three have 3-residue deletions in this region. The efficiencies of the mutants for catalysis of the complete reaction as well as the E-His + ATP $\leftrightarrow$ E-His-PP-AMP partial reaction at the $\mathrm{N}$-terminal domain and the $\mathrm{E}$-His $+\mathrm{PEP} \leftrightarrow \mathrm{E}$-His-P + pyruvate reaction at the $\mathrm{C}$-terminal domain were measured to assess linker function. Three linker mutants are highly active catalysts at both active sites, and the fourth is highly active at one site but not the other. These results are interpreted as evidence against coordinated linker movement, and suggest instead that the linkers move independently as the central domain travels between active sites. It is hypothesized that while the linkers play a passive role in central domain-terminal domain docking, their structural design minimizes the conformational space searched in the diffusion process.
\end{abstract}

Pyruvate phosphate dikinase (PPDK) ${ }^{1}$ catalyzes the interconversion of ATP, $\mathrm{P}_{\mathrm{i}}$, and pyruvate with AMP, $\mathrm{PP}_{\mathrm{i}}$, and PEP (1). $\mathrm{Mg}^{2+}$ and $\mathrm{NH}_{4}{ }^{+}$ions are required cofactors. The reaction pathway consists of the reversible transfer of the ATP $\gamma$-phosphoryl group to $\mathrm{P}_{\mathrm{i}}$ and the $\beta$-phosphoryl group to pyruvate (Scheme 1) (2). This process is mediated by a carrier histidine [His455 in C. symbiosum PPDK (3)], which first displaces AMP from the $\beta$-phosphoryl of ATP, forming a pyrophosphorylated enzyme intermediate (E-His-PP) (3, 4). Next, phosphoryl transfer occurs from the terminal $\gamma$-phosphoryl group of the pyrophosphorylhistidine in E-His$\mathrm{PP}$ to $\mathrm{P}_{\mathrm{i}}$, forming inorganic pyrophosphate $\left(\mathrm{PP}_{\mathrm{i}}\right)$ and a phosphorylated enzyme intermediate (E-His-P). In the final

\footnotetext{
$\doteqdot$ This work was supported by NIH Grant GM 36260 .

* To whom correspondence should be addressed. E-mail: dd39@ unm.edu, Fax: 505-277-6202, Phone: 505-277-3383.

${ }^{1}$ Abbreviations: PPDK, pyruvate phosphate dikinase; N-linker, the linker which connects the N-terminal domain and central domain in PPDK; C-linker, the linker which connects the $\mathrm{C}$-terminal domain and central domain in PPDK; NDP, N-linker deletion at pivot site; NIBP, $\mathrm{N}$-linker insertion below the pivot site; NDBP, $\mathrm{N}$-linker deletion below the pivot site; CDP, C-linker deletion at the pivot site; CIP, C-linker insertion at the pivot site; ATP, adenosine $5^{\prime}$-triphosphate; AMP or AdeP $\alpha$, adenosine 5'-monophosphate; PEP, phosphoenolpyruvate; $\mathrm{NADH}$, dihydronicotinamide adenine dinucleotide; Hepes, $N$-(2-hydroxyethyl)piperazine- $N^{\prime}$-2-ethanesulfonic acid; HPLC, high-performance liquid chromatography.
}

Scheme 1

Partial Reaction 1:

E-His $+\operatorname{AdeP}_{\alpha} \mathbf{P}_{\beta} \mathbf{P}_{\gamma} \rightarrow$ E-His- AdeP $_{\alpha} \mathbf{P}_{\beta} \mathbf{P}_{\gamma} \rightarrow$ E-His- $\mathbf{P}_{\beta} \mathbf{P}_{\gamma} \cdot$ AdeP $_{\alpha}$

Partial Reaction 2:

E-His- $\mathrm{P}_{\beta} \mathrm{P}_{\gamma} \cdot$ AdeP $_{\alpha}+\mathrm{P}_{\mathbf{i}} \rightarrow$ E-His- $\mathrm{P}_{\beta} \mathrm{P}_{\gamma} \cdot \mathrm{AdeP}_{\alpha} \cdot \mathrm{P}_{\mathrm{i}} \rightarrow$ E-His-P $\mathrm{P}_{\beta} \cdot \mathrm{AdeP}_{\alpha} \cdot \mathrm{P}_{\gamma} \mathrm{P}_{\mathrm{i}}$

Partial Reaction 3:

E-His- $\mathrm{P}_{\beta}+$ pyruvate $\rightarrow$ E-His- $\mathrm{P}_{\beta}$-pyruvate $\rightarrow$ E-His-PEP $\beta$

step, the $\beta$-phosphoryl group in E-His-P is transferred from E-His-P to pyruvate to generate phosphoenolpyruvate (PEP).

The $C$. symbiosum PPDK is a homodimer of $96 \mathrm{kDa}$ subunits. The X-ray crystal structure shows that each subunit is organized into three consecutive structural domains (5). As illustrated in Figure 1 (top structure), these include an $\mathrm{N}$-terminal domain (residues $1-340$ ) connected by an $\alpha$-helical linker (residues 341-389) to the central domain (residues 390-504), which in turn is connected by an $\alpha$-helical linker (residues 505-533) to the C-terminal domain (residues 554-874). The ATP/ $\mathrm{P}_{\mathrm{i}}$ active site is located at the concave surface of the N-terminal domain, the carrier His 455 on the convex surface of the central domain, and the pyruvate 


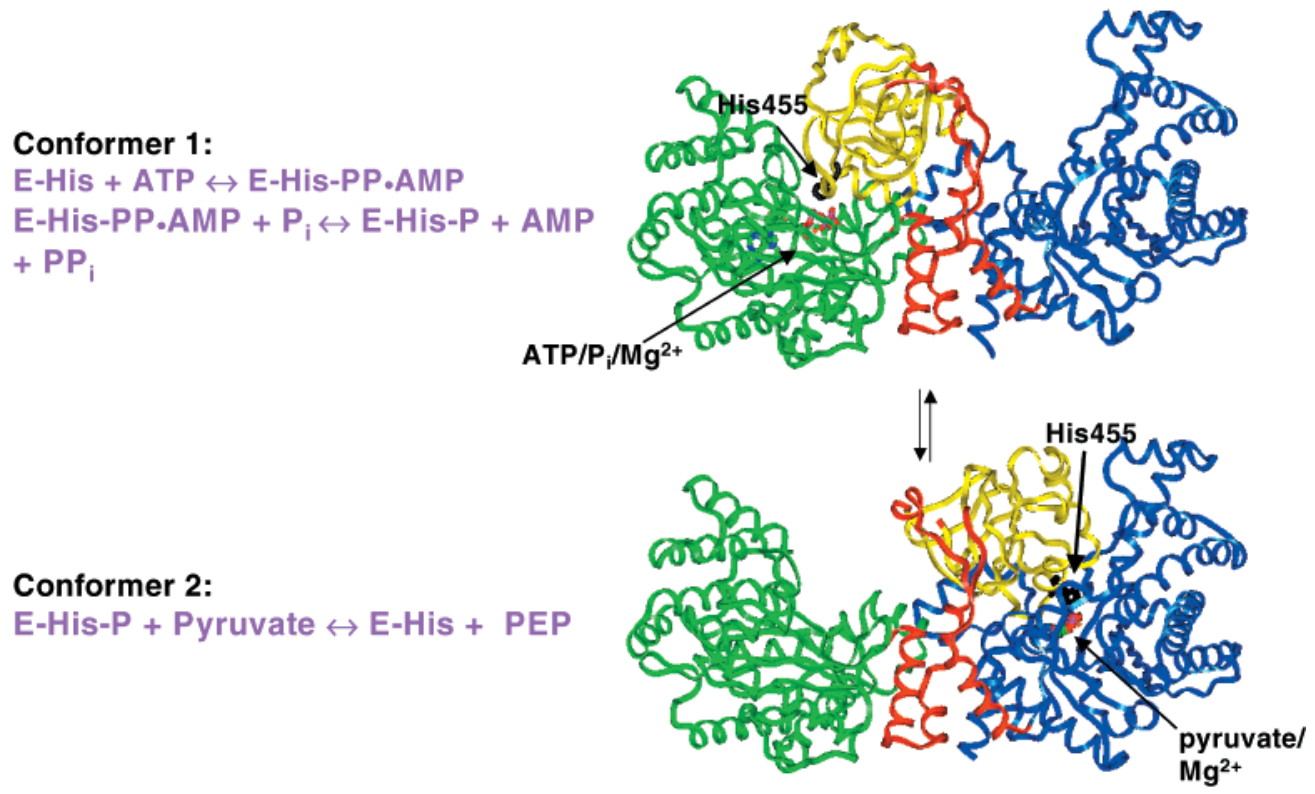

FIGURE 1: Conformer 1: Ribbon diagram of the C. symbiosum PPDK monomer generated from the X-ray coordinates of the apoPPDK structure reported in (5) using INSIGHTII. The N-terminal domain active site is identified by the modeled substrate and cofactor ligands. Conformer 2: Ribbon diagram of the C. symbiosum PPDK monomer modeled from conformer 1 . The C-terminal domain active site is identified by the modeled substrate and cofactor ligands. The N-terminal domain (green) and C-terminal domain (blue) are connected to the central domain (yellow) by helical linkers (red). The His455 is black.

active site at the concave surface of the C-terminal domain. The central domain is bound to the N-terminal domain, placing the side chain of His455 in close proximity to the $\mathrm{ATP} / \mathrm{P}_{\mathrm{i}}$ active site. This structure corresponds to a conformer (henceforth referred to as conformer 1) competent to catalyze partial reactions 1 and 2 but not partial reaction 3. Catalysis of partial reaction 3 requires that the central domain bind to the C-terminal domain, thus forming a second protein conformer. This conformer (named conformer 2) can be modeled by rotating or "pivoting" about the two linkers, thereby transferring the central domain from its binding site at the $\mathrm{N}$-terminal domain to that at the C-terminal domain (Figure 1, bottom structure), and positioning His445 for inline attack at the phosphoryl group of the bound PEP substrate (5).

Separate site catalysis requires continual cycling between two conformational states. As illustrated in Figure 2, for one partial reaction alone, the central domain must first dissociate from the active site to allow the substrate to bind, then reassociate for catalysis, and, finally, dissociate once more to permit product release. ${ }^{2}$ The movement of the central domain between the active sites is under the control of the two helical linkers.

In this paper, the two helical linkers (illustrated in Figure 3) are referred to as the N-linker (connecting the central domain to the $\mathrm{N}$-terminal domain) and the C-linker (connecting the central domain to the C-terminal domain). The N-linker "begins" at residue 340 and "ends" at residue 399 and is thus 59 amino acids long. Residues $340-377$ of the $\mathrm{N}$-linker form a helix -turn-helix motif (red), which packs

${ }^{2}$ The X-ray crystal structure of conformation 1 shows that the entrance to the active site of the N-terminal domain is blocked by the central domain. Likewise, the modeled structure of conformer 2 shows that the C-terminal domain active site entrance is blocked by the central domain.

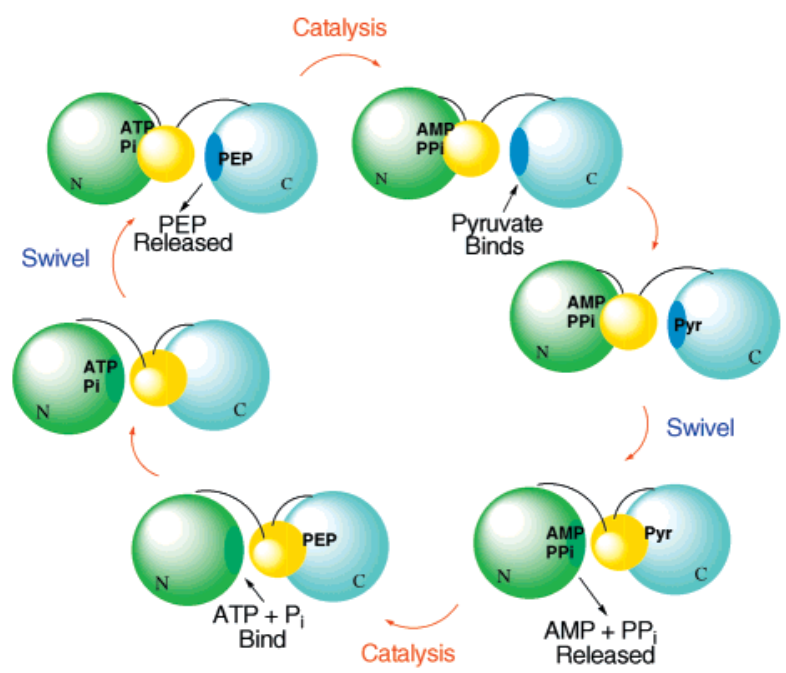

FIGURE 2: Cartoon illustrating the multiple conformational changes required for completion of a catalytic cycle in PPDK. The $\mathrm{N}$-terminal domain is green, the central domain yellow, and the C-terminal domain blue.

against the surface of the $\mathrm{N}$-terminal domain (green) on one side and against the helical region of the C-linker on the other (red in main structure, pink in inset). Residues 378389 form a largely solvated segment of loop-helix structure (colored black). At residue 390 and continuing into the central domain (yellow) at residue 399, the chain assumes a $\beta$-structure that engages in interstrand $\mathrm{H}$-bond interaction with the C-linker (gold). The C-linker consists of residues 499-533 and is thus only 34 amino acids long. Residues 499-504 assume a $\beta$-structure (gold) that engages in the before-mentioned $\mathrm{H}$-bond interaction with the $\mathrm{N}$-linker (gold). The solvated, irregular segment of the C-linker consists of residues 505-519 and runs parallel to the solvated segment of the N-linker (black). This section of linker 


\section{Linker Anatomy}

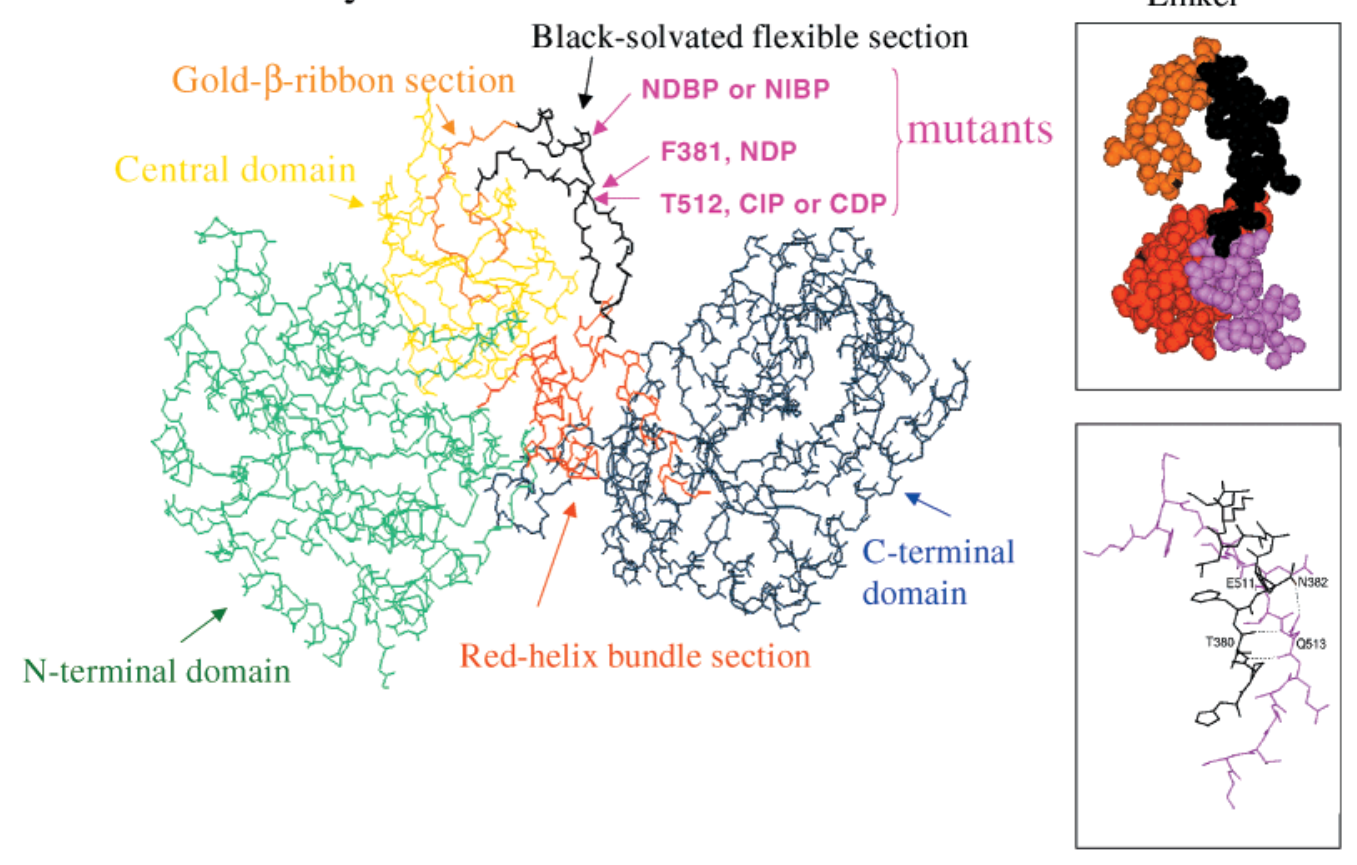

FIGURE 3: Stick diagram of the linker region of $C$. symbiosum PPDK monomer (without side chains) generated from the X-ray coordinates of the PPDK structure reported in (5) using INSIGHTII. The $\alpha$-helical segments used to connect with the N-terminal domain (green) (residues 340-377) and C-terminal domain (blue) (residues 520-533) are red, the solvated middle segments of the linkers (residues 378389 and residues 505-519) are black, and the $\beta$-strand segments (residues 390-399 and residues 499-504) used to connect with the central domain (yellow) are gold. The pivot residues F381 and T512 are identified with arrows, as are the sites used for the amino acid insertions and deletions. Top inset: Space-filling diagram of the linker region. The same color scheme is used except for the $\alpha$-helical section of the C-linker which is shown in pink. Bottom inset: Sites of H-bonding interaction (shown by dotted line) between solvated region of $\mathrm{N}$-linker (black) and solvated region of C-linker (magenta).

engages in several H-bond interactions with the solvated region of the N-linker as illustrated in Figure 3. Residues $520-533$ form a $\alpha$-helical segment (red in the main structure and pink in the inset) that packs against the helix-turnhelix motif of the $\mathrm{N}$-linker (red) on one side and the surface of the C-terminal domain (blue) on the other. Interconversion between the two conformers pictured in Figure 1 may occur via the rotation of the $\mathrm{C} \alpha-\mathrm{N}$ and/or $\mathrm{C} \alpha-\mathrm{C}=\mathrm{O}$ bonds of one or more residues located at the solvated regions of the two linkers. The model of conformer 2 shown in Figure 1 was generated through manual rotation of the linker backbones at residues F381 (N-linker) and T512 (C-linker) (see Figure 3) (5). For this reason only, residues F381 and T512 are referred to as the "pivot residues". In the absence of an $\mathrm{X}$-ray crystal structure of conformer 2, we are not certain where the actual site of rotation is located.

The close association of the two linkers observed from the X-ray crystal structure, even at the solvated regions, is suggestive of the synchronized linker movement. Indeed, coordinated linker movement provides a mechanism for ligand binding at one active site to induce the movement of the central domain from the other. Specifically, a ligandinduced conformational change effecting the linker-terminal domain interface may set off a rotational motion at the pivot site, and it, in turn, the translocation of the central domain.

The goal of the work reported in this paper is to distinguish between two views of linker function: directed central domain movement and central domain movement by limited diffusion. The experimental approach was to mutate the linkers at the solvated region (see Figure 3), thus taking them out of sequence register, and, with that, removing any structural basis for their association. The linkers were taken out of register by inserting four Ala residues in one linker and not in the other, or by deleting three residues from one linker and not the other. The mutants made are illustrated in Figure 4. If the two linkers move as a single unit, held together by interstrand interaction, then it is expected that lengthening or shortening one linker will disrupt this interaction, and hence the synchronized movement. On the other hand, if the two linkers move independently, then adding or subtracting residues from one linker should not impair central domain docking (provided that the linker is long enough for the central domain to reach its target).

The catalytic efficiencies of the insertion and deletion mutants were measured to determine if the structural changes made impair the docking of the central domain at the $\mathrm{N}$-terminal or $\mathrm{C}$-terminal domains. Impaired docking will occur if the orientation of the central domain at the interface of the terminal domain is altered, or if the residence time of the central domain at the terminal domain is too short or too long. Incorrect orientation will mean that the carrier His455 is not positioned for reaction within the active site. If the residence time is too short, the domains will dissociate prematurely. Prolonged residence time at one terminal domain will cause a delay in initiating the reaction at the other terminal domain. Any one of these changes will impair catalysis and can therefore be detected by measuring the kinetic properties of the mutants.

In the following text, we report the kinetic properties measured for the five PPDK linker mutants pictured in Figure 


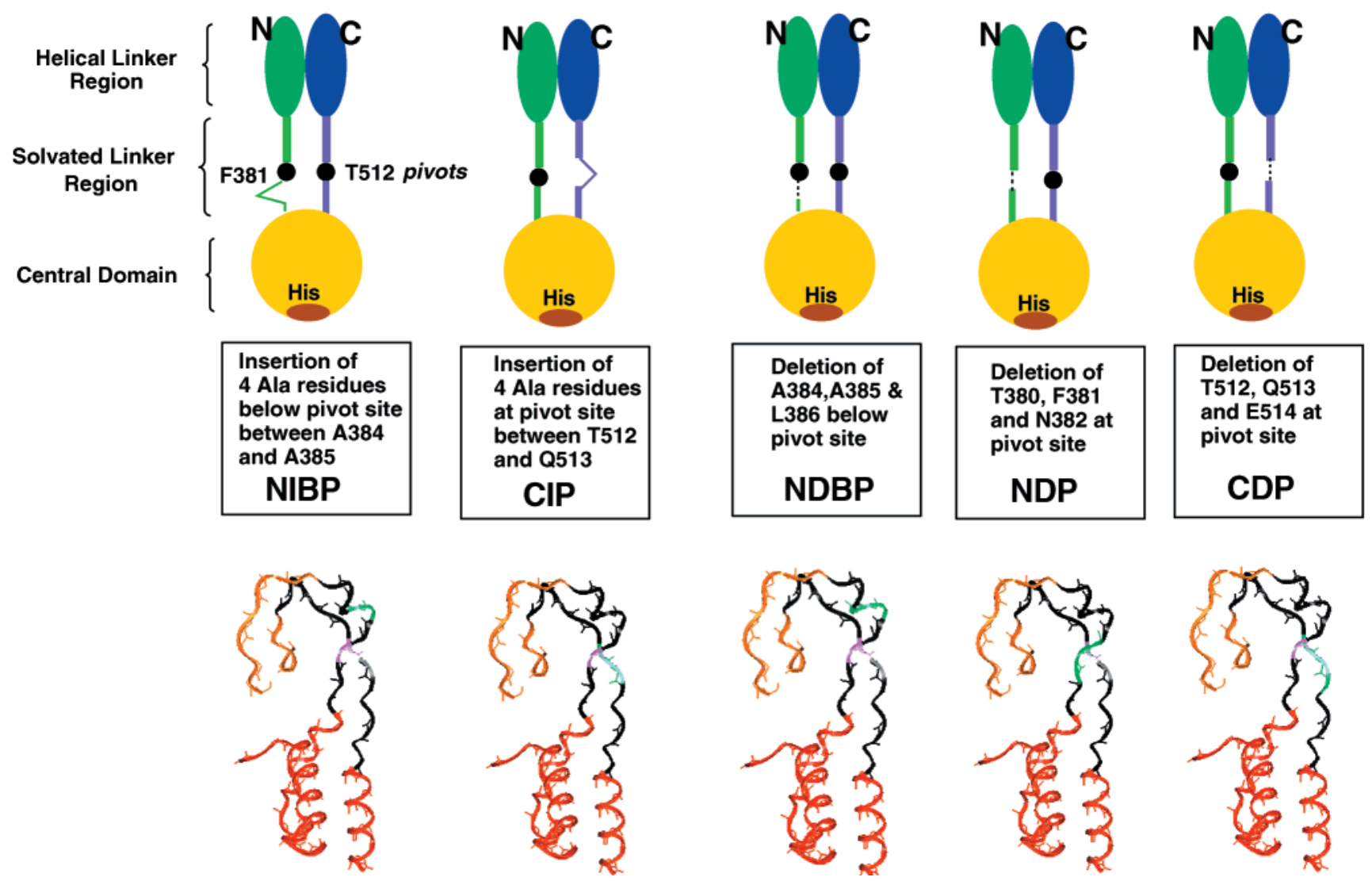

FIGURE 4: Top: Cartoon illustration of the linker mutants analyzed in this study. Middle: Nomenclature used for the mutants. Bottom: Locations of pivot sites (pink) and mutation site (blue) within the solvated region (black) of the linker mutant. The central domain connection region is gold, and the terminal domain connection region is red. See Figure 3 for the structural context of the linker.

4. Based on these results, it is concluded that linker motion is not coordinated. It is hypothesized that while the linkers play a passive role in central domain-terminal domain docking, their design minimizes the conformational space searched during diffusion of the central domain between terminal domains.

\section{EXPERIMENTAL PROCEDURES}

Construction of Linker Mutants. Mutant genes were prepared from the plasmid pACYC184-D12 (6) using PCR techniques analogous to those described in (7). The PCR primers used to generate the poly-alanine insertion mutants were 36 bases in length including the 12-base codon $(\mathrm{GCT})_{4}$. The primers for producing deletion mutants were 24 bases in length, expanding 12 bases at each side of the deletion site. All primers were synthesized by Gibco BRL Life Science Products. KpnI and Bst XI restriction sites were employed in the construction of the linker mutants. The sequences of the isolated mutant genes were determined by the Center for Agricultural Biotechnology at the University of Maryland. Wild-type and mutant PPDK genes were expressed in E. coli JM101 cells and the protein products purified to homogeneity (as judged by SDS-PAGE analysis) as described in (7). The yields of all mutant proteins are $20-25 \mathrm{mg} / \mathrm{g}$ of cell, comparable to the yield of wild-type PPDK. The chromatographic properties of the mutant proteins as well as their stability to storage in buffered solutions at $4{ }^{\circ} \mathrm{C}$ were observed to be very similar to the chromatographic properties and stability of the wild-type enzyme.
Steady-State Kinetic Measurements. AMP $+P P_{i}+P E P$ $\leftrightarrow$ ATP $+P_{i}+$ Pyruvate Reaction. Spectrophotometric Assay. Initial velocities were measured as a function of the concentration of the varied substrate (in a range of 0.5-10fold $K_{\mathrm{m}}$ ) at fixed, saturating concentrations of cosubstrates (0.5 mM AMP, $0.5 \mathrm{mM}$ PEP, $1 \mathrm{mM} \mathrm{PP}$ ) and metal ion cofactors $\left(5 \mathrm{mM} \mathrm{MgCl} 2\right.$ and $\left.10 \mathrm{mM} \mathrm{NH}_{4} \mathrm{Cl}\right)$ in $20 \mathrm{mM}$ imidazole $\left(\mathrm{pH} 6.8,25{ }^{\circ} \mathrm{C}\right)$. The initial velocity data were analyzed using eq 1 and the computer program of Cleland (8). The $k_{\text {cat }}$ was calculated from $V_{\max } /[\mathrm{E}]$ :

$$
v_{\mathrm{o}}=V_{\max }[\mathrm{S}] /\left(K_{\mathrm{m}}+[\mathrm{S}]\right)
$$

where $v_{\mathrm{o}}$ is the initial velocity, [E] is the enzyme concentration, [S] is the substrate concentration, $V_{\max }$ is the maximum velocity, and $K_{\mathrm{m}}$ is the Michaelis constant.

PPDK-Catalyzed Single Turnover Reactions of [ $\left.{ }^{32} P\right] P E P$. $\left[{ }^{32} \mathrm{P}\right] \mathrm{PEP}$ was synthesized from $\left[\beta-{ }^{32} \mathrm{P}\right] \mathrm{ATP}$ according to the procedure described previously (4). Single turnover reactions of $40 \mu \mathrm{M}$ wild-type or mutant PPDK, $5 \mu \mathrm{M}\left[{ }^{32} \mathrm{P}\right] \mathrm{PEP}, 2.5$ $\mathrm{mM} \mathrm{MgCl} 2$, and $10 \mathrm{mM} \mathrm{NH}_{4} \mathrm{Cl}$ in $50 \mathrm{mM} \mathrm{K}^{+}$-Hepes $(\mathrm{pH}$ $7.0,25^{\circ} \mathrm{C}$ ) were carried out in a rapid-quench instrument from KinTek Instruments. Reactions were initiated by mixing $32 \mu \mathrm{L}$ of buffered enzyme/cofactors with $32 \mu \mathrm{L}$ of buffered substrate and then terminated at specified times with 182 $\mu \mathrm{L}$ of $0.6 \mathrm{M} \mathrm{HCl}$. The protein was precipitated from the quenched solutions by vigorous mixing with $\mathrm{CCl}_{4}$ and separated by centrifugation. The protein pellet (dissolved in $500 \mu \mathrm{L}$ of boiling $\left.10 \mathrm{~N} \mathrm{H}_{2} \mathrm{SO}_{4}\right)\left(\left[{ }^{32} \mathrm{P}\right] \mathrm{E}-\mathrm{His}-\mathrm{P}\right)$ and supernatant $\left(\left[{ }^{32} \mathrm{P}\right] \mathrm{PEP}\right)$ were analyzed for ${ }^{32} \mathrm{P}$ by liquid scintillation 
A

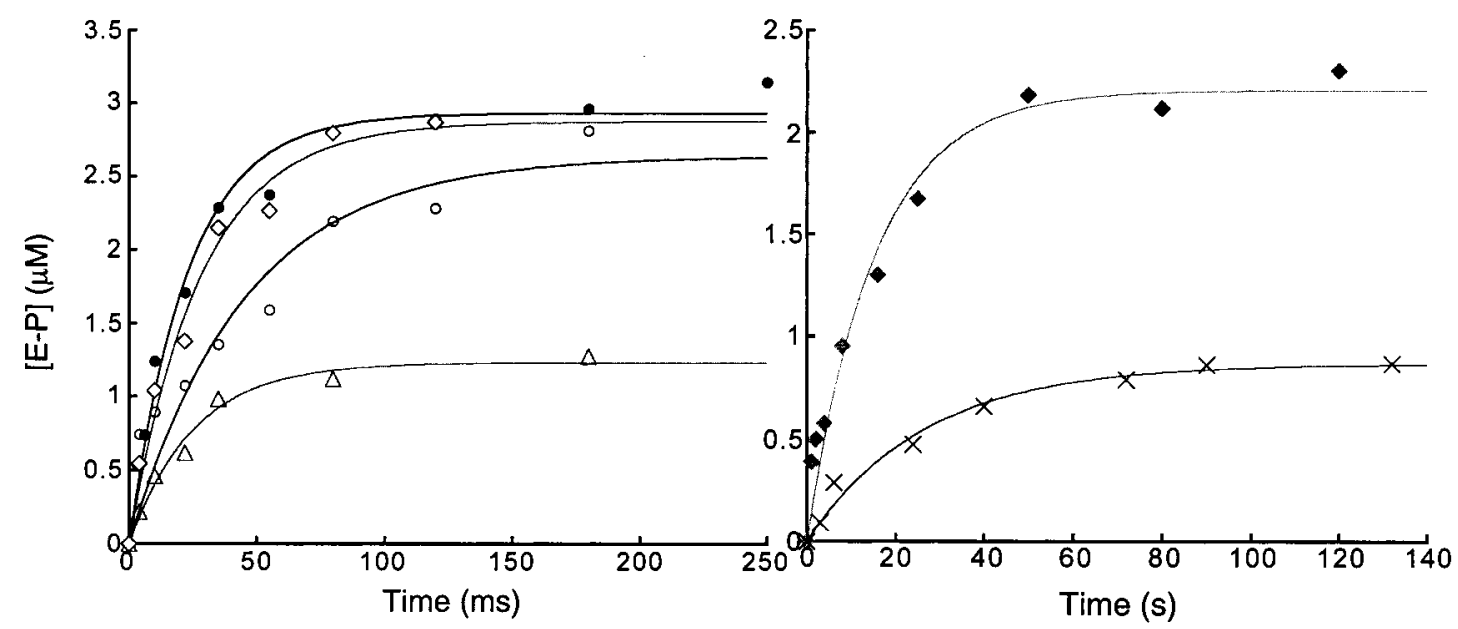

FIGURE 5: Time courses for [ $\left.{ }^{32} \mathrm{P}\right] \mathrm{E}-\mathrm{His}-\mathrm{P}$ formation in the single turnover reaction of $40 \mu \mathrm{M}$ wild-type or mutant PPDK, $5 \mu \mathrm{M}\left[{ }^{32} \mathrm{P}\right] \mathrm{PEP}$, $2.5 \mathrm{mM} \mathrm{MgCl}_{2}$, and $10 \mathrm{mM} \mathrm{NH}_{4} \mathrm{Cl}$ in $50 \mathrm{mM} \mathrm{K}^{+}$-Hepes (pH 7.0, $25^{\circ} \mathrm{C}$ ). (A) Wild-type PPDK $(\bullet)$, NIBP (O), NDBP PPDK $(\triangle)$, CIP $\operatorname{PPDK}(\diamond)$, and NDP PPDK $(\times)$. (B) CDP PPDK $(\diamond)$. The data are fitted with eq 2.

counting. The rate data were fitted to a single exponential equation (eq 2) using the computer program KaleidaGraph to obtain the observed rate constants for the single turnover reaction:

$$
[\mathrm{B}]_{t}=[\mathrm{B}]_{\infty} *\left[1-\exp \left(-k_{\mathrm{obs}} * t\right)\right]
$$

where $[\mathrm{B}]_{t}$ is the substrate concentration at time $t,[\mathrm{~B}]_{\infty}$ is the substrate concentration at equilibrium, and $k_{\mathrm{obs}}$ is the observed rate constant for the reaction.

Single Turnover Reactions of $\left[{ }^{14} \mathrm{C}\right] A T P .\left[{ }^{14} \mathrm{C}\right] \mathrm{ATP}$ (specific activity $500 \mu \mathrm{Ci} / \mathrm{mmol}$ ) was synthesized from $\left[{ }^{14} \mathrm{C}\right] \mathrm{AMP}$ (obtained from NEN Life Science Products) as described in (4). Single turnover reactions of $40 \mu \mathrm{M}$ wild-type or mutant PPDK, $10 \mu \mathrm{M}\left[{ }^{14} \mathrm{C}\right] \mathrm{ATP}, 2.5 \mathrm{mM} \mathrm{CoCl}_{2}$, and $10 \mathrm{mM} \mathrm{NH}_{4^{-}}$

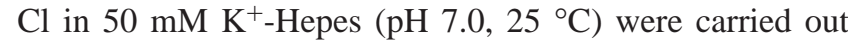
using the KinTek rapid-quench device as described in the previous section. The protein was removed from the reaction mixture by centrifugation using a $500 \mu \mathrm{L}$ filter (molecular weight cutoff 30 000) purchased from Pall Gelman Inc. The unconsumed $\left[{ }^{14} \mathrm{C}\right] \mathrm{ATP}$ and the $\left[{ }^{14} \mathrm{C}\right] \mathrm{AMP}$ product were separated by HPLC using a Beckman Ultrasphere C18 reversed-phase column and $25 \mathrm{mM} \mathrm{KH}_{2} \mathrm{PO}_{4}, 2.5 \%$ triethylamine, and 5\% methanol as the mobile phase. The fractions containing ATP and AMP were quantitated for ${ }^{14} \mathrm{C}$ radioactivity by liquid scintillation counting. The rate data were fitted to a single exponential equation (eq 2) as described in the previous section.

\section{RESULTS}

Linker Mutants. The structural features of the two linkers have been described in the introduction. In brief, the solvated and seemingly flexible midsections of the linkers (colored black in Figure 3) are flanked by two rigid, domainconnecting segments (colored red and gold). For the N-linker, the midsection is comprised of residues $378-389$ with F381 serving as the pivot site used to generate conformer 2 of Figure 1. For the C-linker, the midsection is comprised of residues 505-519 with T512 serving as the pivot site. To study structural determinants in linker movement, mutations were made at, or near, residues F381 and T512.
Two types of linker insertion mutants were prepared (see Figure 4). One of these (NIBP, 4-Ala inserted between residues A384 and A385) contains an additional turn to the short $\alpha$-helical segment that resides just below the pivot residue and just above the $\beta$-segment leading into the central domain. The other linker insertion mutant (CIP, 4-Ala inserted between residues T512 and Q513) is extended by four residues at the C-linker pivot site. Three types of deletion mutants were prepared. Two these mutants (NDP, residues T380, F381, and N382 deleted; and CDP, residues T512, Q513, and E514 deleted) are missing the pivot residue as well as its two neighbors. The third mutant (NCBP, residues $\mathrm{A} 384, \mathrm{~A} 385$, and $\mathrm{L} 386$ deleted) is missing one turn of the short $\alpha$-helical segment positioned just below the pivot residue of the N-linker. The five mutants are thus NIBP, CIP, NDBP, NDP, and CDP. The acronyms used in naming these linker mutants are $\mathrm{N}$ or $\mathrm{C}$ for $\mathrm{N}$-linker or $\mathrm{C}$-linker, I or $\mathrm{D}$ for insertion or deletion, and $\mathrm{BP}$ or $\mathrm{P}$ for below the pivot residue (F381 or T512) or at the pivot residue.

Wild-Type and Mutant PPDK Catalysis of the E-His + $P E P \rightarrow$ E-His-P + Pyruvate Partial Reaction at the $C$-Terminal Domain Active Site. This partial reaction is catalyzed by conformer 2 (Figure 1). However, prior to catalysis, the PEP must first bind to conformer 1, since the entrance to the $\mathrm{C}$-terminal domain active site is blocked by the central domain in conformer $2 .{ }^{2}$ The reaction must, therefore, start with enzyme conformer 1 and ensue with enzyme conformer 2 (see steps shown in Figure 2). Since a single turnover reaction is monitored, product release is not necessary, and, therefore, neither is the switch from conformer 1 to conformer 2 after catalysis.

The observed rate constant for a single turnover reaction was measured by reacting limiting $\left[{ }^{32} \mathrm{P}\right] \mathrm{PEP}(5 \mu \mathrm{M})$ with $\mathrm{Mg}(\mathrm{II})$-activated wild-type or mutant PPDK $(40 \mu \mathrm{M})$ in a rapid-quench apparatus. The reactions were quenched with acid after specific incubation times, and the enzyme was precipitated and then quantitated by liquid scintillation counting. The observed rate constant $\left(k_{\mathrm{obs}}\right)$ for the reaction was determined from a first-order plot of $\left[{ }^{32} \mathrm{P}\right] \mathrm{E}-\mathrm{His}-\mathrm{P}$ concentration vs reaction time (see Figure 5). The observed equilibrium constant $\left(K_{\text {eq }}\right)$ for the reaction was derived from 
Table 1: Single Turnover Rate Constants for Wild-Type and Mutant PPDK (See Figure 4 for Description) Catalysis of E-His + $\left.{ }^{[32} \mathrm{P}\right] \mathrm{PEP} \rightarrow\left[{ }^{32} \mathrm{P}\right] \mathrm{E}-\mathrm{His}-\mathrm{P}+$ Pyruvate Reaction ${ }^{a}$

\begin{tabular}{lcclcc}
\hline enzyme & $k_{\text {obs }}\left(\mathrm{s}^{-1}\right)$ & $K_{\text {eq }}$ & enzyme & $k_{\text {obs }}\left(\mathrm{s}^{-1}\right)$ & $K_{\text {eq }}$ \\
\hline wild-type & $43 \pm 4$ & 0.60 & NIBP & $22 \pm 6$ & 0.52 \\
CIP & $35 \pm 5$ & 0.60 & NDBP & $40 \pm 5$ & 0.24 \\
CDP & $0.065 \pm 0.009$ & 0.46 & NDP & $0.037 \pm 0.006$ & 0.14
\end{tabular}

${ }^{a}$ Single turnover reactions contained $40 \mu \mathrm{M}$ enzyme, $5 \mu \mathrm{M}\left[{ }^{32} \mathrm{P}\right]-$ PEP, $2.5 \mathrm{mM} \mathrm{MgCl}_{2}$, and $10 \mathrm{mM} \mathrm{NH}_{4} \mathrm{Cl}$ in $50 \mathrm{mM} \mathrm{K}{ }^{+}$-Hepes $\left(\mathrm{pH} 7.0,25^{\circ} \mathrm{C}\right)$.

the ratio of $\left[{ }^{32} \mathrm{P}\right] \mathrm{E}-\mathrm{His}-\mathrm{P}$ concentration to $\left[{ }^{32} \mathrm{P}\right] \mathrm{PEP}$ concentration existing upon completion of the reaction.

The enzyme participates in the reaction equilibrium E-His $+\left[{ }^{32} \mathrm{P}\right] \mathrm{PEP} \leftrightarrow \mathrm{E}-\mathrm{His} \cdot\left[{ }^{32} \mathrm{P}\right] \mathrm{PEP} \leftrightarrow\left[{ }^{32} \mathrm{P}\right] \mathrm{E}-\mathrm{His}-\mathrm{P} \cdot$ pyruvate $\leftrightarrow$ $\left.{ }^{[32} \mathrm{P}\right] \mathrm{E}-\mathrm{His}-\mathrm{P}+$ pyruvate as a substrate and a product. Thus, the overall $K_{\text {eq }}$ is determined by the dissociation constants of E-His: $\left[{ }^{32} \mathrm{P}\right] \mathrm{PEP}(170 \mu \mathrm{M})$ and $\left.{ }^{[32} \mathrm{P}\right] \mathrm{E}-\mathrm{His}-\mathrm{P} \cdot$ pyruvate $(75$ $\mu \mathrm{M})$ and by the internal equilibrium constant $\left(\left[{ }^{32} \mathrm{P}\right] \mathrm{E}-\mathrm{His}-\right.$ $\mathrm{P} \cdot$ pyruvate/E-His $\left.\cdot\left[{ }^{32} \mathrm{P}\right] \mathrm{PEP}=1\right)(9)$. The dissociation constants, as well as the internal equilibrium constant, may change if the binding of the central domain with the terminal domains is altered by mutation. A change in these constants, in turn, may change the $K_{\text {eq }}$ for the partial reaction. The $k_{\text {obs }}$ for the partial reaction can be effected by the linker mutation if it causes a change in the orientation and/or residence time of the docked central domain, since either can decrease the rate at which the bound $\left[{ }^{32} \mathrm{P}\right] \mathrm{PEP}$ and His455 react.

Under the reaction conditions employed, the $K_{\text {eq }}$ for the partial reaction (i.e., total $\left[{ }^{32} \mathrm{P}\right] \mathrm{E}-\mathrm{His}-\mathrm{P} /$ total $\left[{ }^{32} \mathrm{P}\right] \mathrm{PEP}$ ) catalyzed by wild-type PPDK is 0.60 , and the observed rate, $k_{\mathrm{obs}}$, for the conversion of [ $\left.{ }^{32} \mathrm{P}\right] \mathrm{PEP}$ to [ $\left.{ }^{32} \mathrm{P}\right] \mathrm{E}-\mathrm{His}-\mathrm{P}$ is $43 \mathrm{~s}^{-1}$. The $K_{\text {eq }}$ and $k_{\text {obs }}$ values measured for partial reactions catalyzed by the five linker mutants are listed in Table 1 . The mutant $\mathrm{CIP}$, in which the $\mathrm{C}$-linker is lengthened by four Ala residues at the pivot site, displays the same values for $K_{\text {eq }}$ and $k_{\text {obs }}$ as wild-type PPDK. Insertion of four Ala residues below the pivot site in NIBP causes only a modest reduction in these values. Thus, an increase in linker length does not disrupt catalysis at the C-terminal domain.

Deletions made at the pivot sites have deleterious effects on catalysis. The $k_{\text {obs }}$ values for CDP and NDP are reduced 1000 -fold. In CDP, the $K_{\text {eq }}$ is 0.46 , and in NDP, it is reduced to 0.14 . If, on the other hand, the deletion of three residues from the N-linker is made at the short $\alpha$-helix, located just below the pivot site, $k_{\mathrm{obs}}$ is not reduced. $K_{\mathrm{eq}}$ is, however, reduced to 0.24 , suggesting that some change in the thermodynamics of the reaction has occurred despite the unchanged rate constant.

Wild-Type and Mutant PPDK Catalysis of the E-His + $A T P \rightarrow E$-His-PP•AMP Partial Reaction at the N-Terminal Domain Active Site. This partial reaction is catalyzed by conformer 1, but again, conformer 2 must first bind the ATP before catalysis at the $\mathrm{N}$-terminal domain can ensue (see Figure 2). Once ATP is bound, the enzyme must switch to conformer 1 to catalyze the reaction between His 455 and the ATP $\beta$-P.

The efficiency by which each of the PPDK mutants is able to complete these steps was examined by measuring the apparent rate constant for a single turnover reaction of limiting $\left[{ }^{14} \mathrm{C}\right] \operatorname{ATP}(10 \mu \mathrm{M})$ with Co(II)-activated ${ }^{3}$ wild-type or mutant PPDK $(40 \mu \mathrm{M})$ (time courses shown in Figure 6).
Table 2: Single Turnover Rate Constants for Catalysis of the E-His $+\left[{ }^{14} \mathrm{C}\right]$ ATP $\rightarrow$ E-His-PP. $\left[{ }^{14} \mathrm{C}\right]$ AMP Reaction by Wild-Type and Mutant PPDK (See Figure 4 for Description) ${ }^{a}$

\begin{tabular}{lcclcl}
\hline enzyme & $k_{\text {obs }}\left(\mathrm{s}^{-1}\right)$ & $K_{\text {eq }}$ & enzyme & $k_{\text {obs }}\left(\mathrm{s}^{-1}\right)$ & $K_{\text {eq }}$ \\
\hline wild-type & $300 \pm 70$ & 0.23 & NIBP & $200 \pm 40$ & 0.14 \\
CIP & $218 \pm 7$ & 0.37 & NDBP & $206 \pm 14$ & 0.11 \\
CDP & $0.0044 \pm 0.0008$ & 0.16 & NDP & $\geq 400$ & 0.1 \\
\hline
\end{tabular}

${ }^{a}$ Single turnover reactions contained $40 \mu \mathrm{M}$ enzyme, $10 \mu \mathrm{M}\left[{ }^{14} \mathrm{C}\right]-$ ATP, $2.5 \mathrm{mM} \mathrm{CoCl}_{2}$, and $10 \mathrm{mM} \mathrm{NH}_{4} \mathrm{Cl}$ in $50 \mathrm{mM} \mathrm{K}^{+}$Hepes (pH 7.0, $\left.25^{\circ} \mathrm{C}\right)$.

For wild-type PPDK, the reaction equilibrium E-His $+\left[{ }^{14} \mathrm{C}\right]-$ ATP $\leftrightarrow$ E-His $\cdot\left[{ }^{14} \mathrm{C}\right]$ ATP $\leftrightarrow$ E-His-PP· $\left[{ }^{14} \mathrm{C}\right]$ AMP $\leftrightarrow$ E-His$\mathrm{PP}+\left[{ }^{14} \mathrm{C}\right] \mathrm{AMP}$ is governed by the E-His $\cdot\left[{ }^{14} \mathrm{C}\right] \mathrm{ATP}$ and E-His-PP. $\left[{ }^{14} \mathrm{C}\right]$ AMP dissociation constants of 10 and $<1$ $\mu \mathrm{M},{ }^{4}$ respectively, and by the internal equilibrium constant (E-His-PP· $\left.\left[{ }^{14} \mathrm{C}\right] \mathrm{AMP} / \mathrm{E}-\mathrm{His} \cdot\left[{ }^{14} \mathrm{C}\right] \mathrm{ATP}\right)$ of 0.4 (9). For wildtype PPDK, the observed $K_{\text {eq }}$ for the partial reaction is 0.23 , and the $k_{\mathrm{obs}}$ is $300 \pm 70 \mathrm{~s}^{-1}$. The large error observed in the experimental $k_{\mathrm{obs}}$ is due to the fact that the early time points, which define the steep, initial portion of the rate curve of E-His-PP. $\left[{ }^{14} \mathrm{C}\right] \mathrm{AMP}$ formation, are lost within the mixing time of the rapid-quench instrument used to carry out the reaction.

The rate and equilibrium constants measured for the five linker mutants are listed in Table 2. All mutants except CIP experience a ca. $50 \%$ reduction in $K_{\text {eq. }}$ For CIP, the equilibrium position is shifted $\sim 50 \%$ in favor of product formation $\left(K_{\mathrm{eq}}=0.37\right.$ vs 0.23 for wild-type PPDK). All mutants except CDP catalyze the reaction at the $\mathrm{N}$-terminal domain active site at the same rate (within experimental error) as wild-type PPDK. For CDP, $k_{\mathrm{obs}}=0.0044 \mathrm{~s}^{-1}$, which is $\left(7 \times 10^{4}\right)$-fold smaller than the $k_{\mathrm{obs}}=300 \mathrm{~s}^{-1}$ measured for wild-type PPDK.

Catalysis of the AMP $+P P_{i}+P E P \rightarrow A T P+P_{i}+$ Pyruvate Multi-turnover Reaction. Catalysis of this reaction was measured using steady-state initial velocity techniques. The rate constant $\left(k_{\text {cat }}\right)$ measured for this reaction is not influenced by the kinetics/thermodynamics of substrate binding. In addition, each of the reaction steps, as outlined in Figure 2, must be executed in order to complete the reaction. Thus, impaired catalysis at either active site will reduce $k_{\text {cat }}$, and impaired catalysis at one site can also alter the $K_{\mathrm{m}}$ values measured for substrates reacting at the other catalytic site.

The $k_{\text {cat }}$ and $K_{\mathrm{m}}$ values measured for the five mutants are shown in Table 3. Only the NDP and CDP mutants display large reductions in $k_{\text {cat }}$. The CDP mutant displays "wild-type" $K_{\mathrm{m}}$ values for all three substrates while the NDP mutant displays altered $K_{\mathrm{m}}$ values. In particular, the $K_{\mathrm{m}}$ values for the N-terminal domain substrates AMP and $\mathrm{PP}_{\mathrm{i}}$ are signifi-

\footnotetext{
${ }^{3}$ Substitution of $\mathrm{Co}$ (II) for $\mathrm{Mg}$ (II) as cofactor in the reaction increases both ATP binding to the enzyme and the internal equilibrium, so that the amount of E-His-PP.AMP produced from reaction of $40 \mu \mathrm{M}$ PPDK with $10 \mu \mathrm{M}$ ATP increases from $\sim 5 \%$ for the $\mathrm{Mg}$ (II)-activated enzyme to $\sim 25 \%$ for the $\mathrm{Co}$ (II)-activated enzyme (9). For this reason, the abilities of the PPDK mutants to catalyze the E-His $+\left[{ }^{14} \mathrm{C}\right] \mathrm{ATP} \rightarrow$ E-His-PP. $\left[{ }^{14} \mathrm{C}\right]$ AMP partial reaction were evaluated using Co(II) rather than $\mathrm{Mg}(\mathrm{II})$ as cofactor.

${ }^{4}$ Previous kinetic studies have shown that AMP is not readily released from the E-His-PP-AMP complex but rather from the E-His$\mathrm{P} \cdot \mathrm{AMP}$ complex $(10)$. Thus, the $K_{\mathrm{d}}$ for the E-His-PP·AMP complex is judged to be very small.
} 
A

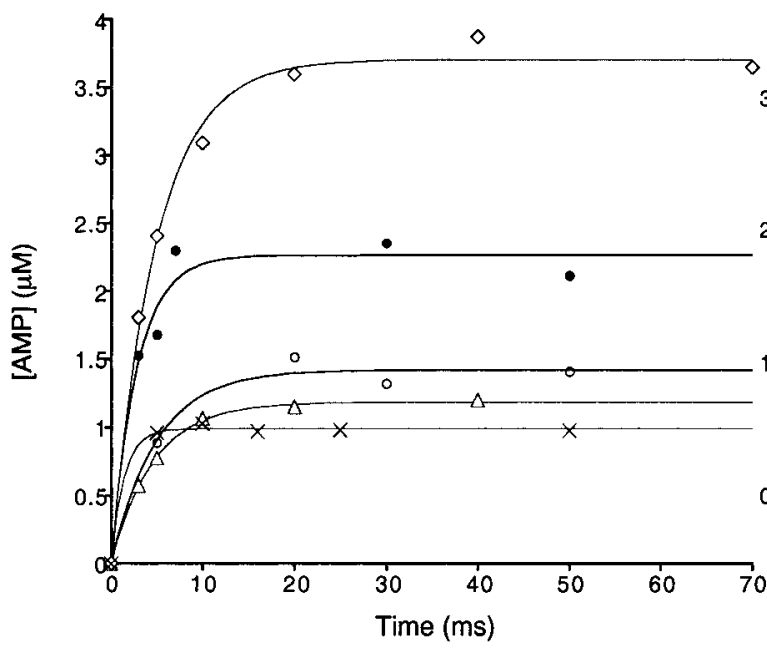

B

FIGURE 6: Time courses for $\left[{ }^{14} \mathrm{C}\right] \mathrm{AMP}$ formation in the single turnover reaction of $40 \mu \mathrm{M}$ wild-type or mutant PPDK, $10 \mu \mathrm{M}\left[{ }^{14} \mathrm{C}\right] \mathrm{ATP}$, $2.5 \mathrm{mM} \mathrm{CoCl}_{2}$, and $10 \mathrm{mM} \mathrm{NH}_{4} \mathrm{Cl}$ in $50 \mathrm{mM} \mathrm{K}^{+}$-Hepes (pH 7.0, $25^{\circ} \mathrm{C}$ ). (A) Wild-type PPDK (O), NIBP PPDK (O), NDBP PPDK $(\triangle)$, CIP PPDK $(\diamond)$, and NDP PPDK $(\times)$. (B) CDP PPDK $(\diamond)$. The data are fitted with eq 2.

Table 3: Steady-State Kinetic Constants for Wild-Type and Mutant PPDK (See Figure 4 for Description) Catalysis of AMP + PP + PEP $\rightarrow$ ATP $+\mathrm{P}_{\mathrm{i}}+$ Pyruvate Reaction $^{a}$

\begin{tabular}{|c|c|c|c|c|c|}
\hline enzyme & $k_{\text {cat }}\left(\mathrm{s}^{-1}\right)$ & $K_{\mathrm{m}}(\mu \mathrm{M})$ & enzyme & $k_{\text {cat }}\left(\mathrm{s}^{-1}\right)$ & $K_{\mathrm{m}}(\mu \mathrm{M})$ \\
\hline $\begin{array}{l}\text { wild-type }(0.006-0.02 \mu \mathrm{M}) \\
\text { vary } \mathrm{AMP}^{b} \\
\text { vary } \mathrm{PP}_{\mathrm{i}}^{c} \\
\text { vary } \mathrm{PEP}^{d}\end{array}$ & $\begin{array}{l}22 \pm 2 \\
28 \pm 1 \\
25 \pm 1\end{array}$ & $\begin{aligned} 9 & \pm 2 \\
88 & \pm 5 \\
27 & \pm 1\end{aligned}$ & $\begin{array}{l}\text { NIBP }(0.025-0.010 \mu \mathrm{M}) \\
\text { vary } \mathrm{AMP}^{b} \\
\operatorname{vary}_{\mathrm{PP}_{\mathrm{i}}^{c}} \\
\text { vary } \mathrm{PEP}^{d}\end{array}$ & $\begin{array}{l}6.3 \pm 0.2 \\
6.5 \pm 0.1 \\
5.7 \pm 0.1\end{array}$ & $\begin{array}{c}8 \pm 1 \\
73 \pm 3 \\
19 \pm 1\end{array}$ \\
\hline 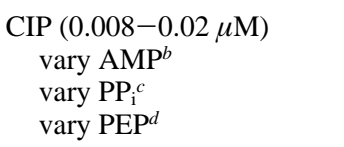 & $\begin{aligned} 17.1 & \pm 0.5 \\
15.6 & \pm 0.3 \\
17 & \pm 1\end{aligned}$ & $\begin{array}{l}53 \pm 5 \\
27 \pm 1 \\
41 \pm 4\end{array}$ & $\begin{array}{l}\text { NDBP }(0.010-0.045 \mu \mathrm{M}) \\
\text { vary } \mathrm{AMP}^{e} \\
\text { vary } \mathrm{PP}_{1}^{f} \\
\text { vary } \mathrm{PEP}^{d}\end{array}$ & $\begin{array}{l}18.6 \pm 0.7 \\
13.7 \pm 0.9 \\
12.7 \pm 0.7\end{array}$ & $\begin{array}{c}9 \pm 1 \\
200 \pm 30 \\
160 \pm 20\end{array}$ \\
\hline $\begin{array}{l}\mathrm{CDP}(2.7-4.5 \mu \mathrm{M}) \\
\text { vary } \mathrm{AMP}^{b} \\
\text { vary } \mathrm{PP}_{\mathrm{i}}^{c} \\
\text { vary } \mathrm{PEP}^{d}\end{array}$ & $\begin{array}{l}0.066 \pm 0.001 \\
0.077 \pm 0.001 \\
0.064 \pm 0.002\end{array}$ & $\begin{array}{l}7.3 \pm 0.2 \\
91 \pm 2 \\
38 \pm 3\end{array}$ & 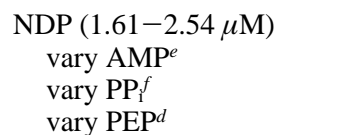 & $\begin{aligned} 0.145 & \pm 0.005 \\
0.131 & \pm 0.003 \\
0.13 & \pm 0.01\end{aligned}$ & $\begin{array}{l}<2^{g} \\
14 \pm 1 \\
580 \pm 70\end{array}$ \\
\hline
\end{tabular}

${ }^{a}$ All reactions were carried out in $20 \mathrm{mM}$ imidazole hydrochloride (pH 6.8) containing $10 \mathrm{mM} \mathrm{NH}_{4} \mathrm{Cl}$ and $5 \mathrm{mM} \mathrm{MgCl}_{2}$ at $25{ }^{\circ} \mathrm{C} .{ }^{b} \mathrm{Reactions}$ contained $1.0 \mathrm{mM} \mathrm{PP}, 0.5 \mathrm{mM}$ PEP. ${ }^{c}$ Reactions contained $0.5 \mathrm{mM}$ AMP, $0.5 \mathrm{mM}$ PEP. ${ }^{d}$ Reactions contained $1.0 \mathrm{mM} \mathrm{PP}$, $0.5 \mathrm{mM}$ AMP. ${ }^{e}$ Reactions contained $1.0 \mathrm{mM} \mathrm{PP}, 2 \mathrm{mM}$ PEP. ${ }^{f}$ Reactions contained $0.5 \mathrm{mM}$ AMP, $2 \mathrm{mM}$ PEP. ${ }^{g}$ The initial velocities of reactions containing NDP and 4,7 , 10,20 , or $50 \mu \mathrm{M}$ AMP were the same within experimental error. Therefore, for NDP the AMP $K_{\mathrm{m}}$ is estimated to be less than $2 \mu \mathrm{M}$.

cantly reduced while the $K_{\mathrm{m}}$ value for the C-terminal domain substrate is increased (20-fold). Among the three highly active mutants (NIBP, CIP, NDBP), only NIBP PPDK shows a significant reduction in $k_{\text {cat }}$ (3-fold). NDBP, on the other hand, displays elevated $K_{\mathrm{m}}$ values for $\mathrm{PP}_{\mathrm{i}}$ (2-fold) and PEP (5-fold) while CIP displays an elevated $K_{\mathrm{m}}$ value for AMP (5-fold).

\section{DISCUSSION}

The two pivot deletion mutants NDP and CDP PPDK display limited catalytic function. NDP PPDK catalyzes substrate turnover at the $\mathrm{N}$-terminal domain active site but not at the C-terminal domain active site, and catalysis in CDP PPDK is impaired at both active sites. While it can be argued that these two mutated linkers are too "short" to allow the central domain to dock at one (NDP mutant) or both active sites (CDP mutant), we have not yet obtained the X-ray crystallographic structures necessary to support this argument. (Neither mutant formed suitable crystals in screening trails.) We also note that the while the deletion made to the $\mathrm{N}$-linker at the pivot site interferes with successful docking of the central domain at the C-terminal domain active site, the deletion made below the pivot site (NDBP mutant) does not. This observation suggests that the removal of one turn of the helical segment below the pivot site (NDBP) does not reduce the reach of the $\mathrm{N}$-linker beyond the critical limit whereas removal of the three residues at the pivot site does. ${ }^{5}$ But again, in the absence of structural data, no firm conclusions can be drawn.

The most significant findings of this study are that the NIBP, CIP, and NDBP PPDK are highly active catalysts, which in turn rules out the requirement of synchronized linker movement during catalytic turnover. In short, this is because the mutations will disrupt the alignment of the linkers and, thus, coordinated movement between them. This, in turn, should reduce $k_{\mathrm{obs}}$. Since catalysis is not affected in a majority of the mutants tested, we conclude that the central domain is able to efficiently dock with the two active sites in the absence of coordinated linker movement.

${ }^{5}$ A reviewer suggested that NDBP PPDK may have lost a turn of the helix without much shortening of the linker. 
The Swivel Model of Linker Function in PPDK Catalysis. The use of a loop segment to connect two domains within a multidomain protein is commonplace. In some proteins, these domain linkers are fully solvated and highly flexible. In such proteins, the tethered domains diffuse as independent bodies $(11-14)$. In the enzyme thioredoxin reductase, the domains do not diffuse together but rather slide along each other's surface as a "ball-and-socket" (15). The linkers are two short $\beta$-strands which simply twist to accommodate the movement of the two domains relative to one another. In other systems, linkers are thought to play a direct role in mediating the interaction which occurs between the protein domains. For example, it has been suggested that in the Src family kinases $(16,17)$ and modular polyketide synthases $(18,19)$ the linkers are able to recognize and bind to protein modules, as necessary for signal transduction and template-driven biosynthesis.

The domain linkers of PPDK do not direct domain movement but rather function as leashes to limit the conformational space available to the diffusing domains. Their structural design appears to be optimized for this task. As shown in Figure 3, the association of helical units located at the connection points to the terminal domain and the alignment of the $\beta$-strands forming the connection points to the central domain limit linker movement to the solvated segment. Independent movement of the linkers within this region may occur freely. Conserved residues located at the interfaced linker surfaces attest to the importance of restrictions placed on motion at the linker termini. In the absence of an X-ray crystal structure of both PPDK conformers, we can only guess, based on computer modeling, on the nature of the linker motion that occurs during the movement of the central domain from the active site of the N-terminal domain to the active site of the C-terminal domain. This motion may be a "swiveling motion" occurring through backbone rotation at or near linker residues F381 and T512. The swivel model of linker motion offers the advantage that the diffusion path of the central domain is highly restricted. Consequently, the efficiency of transfer of the central domain from one active site to the other is comparatively greater than would be expected for that of a freely diffusing body.

The three PPDK domains are believed to have originated as independent proteins. Gene duplication followed by gene fusion may have lead to a primitive three-domain PPDK protein molecule in which short stretches of sequence served as domain linkers. Catalysis within this molecule was dependent on the diffusion of the central domain between the tethered active sites, a definite advantage over intermolecular catalysis. With time, mutation and selection finetuned the structures of these linkers to what they are today. While we cannot ascribe directive functions to the linkers, they do represent a level of sophistication over that of simple tethers.

\section{REFERENCES}

1. Wood, H. G., O'brien, W. E., and Micheales, G. (1977) Adv. Enzymol. Relat. Areas Mol. Biol. 45, 85-155.

2. Reeves, R. E., Menzies, R. A., and Hsu, D. S. (1968) J. Biol. Chem. 243, 5486-5491.

3. Evans, H. J., and Wood, H. G. (1968) Proc. Natl. Acad. Sci. U.S.A. 61, 1448-1453.

4. Carroll, L. J., Mehl, A. F., and Dunaway-Mariano, D. (1989) J. Am. Chem. Soc. 111, 5965-5967.

5. Herzberg, O., Chen, C. C., Kapadia, G., McGuire, M., Carroll, L. J., Noh, S. J., and Dunaway-Mariano, D. (1996) Proc. Natl. Acad. Sci. U.S.A. 93, 2652-2657.

6. Pocalyko, D. J., Carroll, L. J., Martin, B. M., Babbitt, P. C., and Dunaway-Mariano, D. (1990) Biochemistry 29, 1075710765.

7. McGuire, M., Huang, K., Kapadia, G., Herzberg, O., and Dunaway-Mariano, D. (1998) Biochemistry 37, 13463-13474.

8. Cleland, W. W. (1979) Methods Enzymol. 63, 500-513.

9. Mehl, A., Xu, Y., and Dunaway-Mariano, D. (1994) Biochemistry 33, 1093-1102.

10. Wang, H. C., Ciskanik, L., Dunaway-Mariano, D., von der Saal, W., and Villafranca, J. J. (1988) Biochemistry 27, 625633.

11. Hansen, A. P., Petros, A. M., Meadows, R. P., Nettesheim, D. G., Mazar, A. P., Olejniczak, E. T., Xu, R. X., Pederson, T. M., Henkin, J., and Fesik, S. W. (1994) Biochemistry 33, 4847-4864.

12. Moreau, M., deCock, E., Fortier, P. L., Garcia, C., Albaret, C., Blanquet, S., Lallemand, J. Y., and Dardel, F. (1997) J. Mol. Biol. 266, 15-22.

13. Zhou, H. J., McEvoy, M. M., Lowry, D. F., Swanson, R. V., Simon, M. I., and Dahlquist, F. W. (1996) Biochemistry 35, 433-443.

14. Barbato, G., Ikura, M., Kay, L. E., Pastor, R. W., and Bax, A. (1992) Biochemistry 31, 5269-5278.

15. Lennon, B. W., Williams, C. H., Jr., and Ludwig, M. L. (2000) Science 289, 1190-1194.

16. Briggs, S. D., and Smithgall, T. E. (1999) J. Biol. Chem. 274, 26579-26583.

17. Xu, Q. H., Zheng, J., Xu, R., Barany, G., and Cowburn, D. (1999) Biochemistry 38, 3491-3497.

18. Gokhale, R. S., Tsuji, S. Y., Cane, D. E., and Khosla, C. (1999) Science 284, 482-485.

19. Gokhale, R. S., and Khosla, C. (2000) Curr. Opin. Chem. Biol. $4,22-27$.

BI0113061 